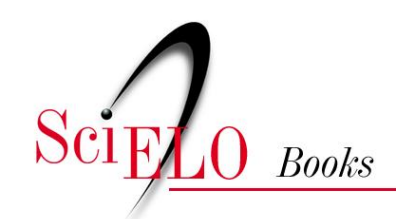

\title{
Feduepb
}

\section{3 - "Ciência e tecnologia para a cidadania" ou Adequação Sociotécnica com o Povo?}

\author{
Renato Dagnino
}

\section{SciELO Books / SciELO Livros / SciELO Libros}

DAGNINO, R. "Ciência e tecnologia para a cidadania" ou Adequação Sociotécnica com o Povo?. In: Tecnologia Social: contribuições conceituais e metodológicas [online]. Campina Grande: EDUEPB, 2014, pp. 89-112. ISBN 978-85-7879-327-2. Available from SciELO Books $<\underline{\text { http://books.scielo.org }>\text {. }}$

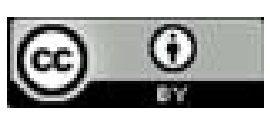

All the contents of this work, except where otherwise noted, is licensed under a Creative Commons Attribution $\underline{4.0 \text { International license. }}$

Todo o conteúdo deste trabalho, exceto quando houver ressalva, é publicado sob a licença Creative Commons Atribição 4.0.

Todo el contenido de esta obra, excepto donde se indique lo contrario, está bajo licencia de la licencia $\underline{\text { Creative }}$ Commons Reconocimento 4.0. 


\section{3}

\section{"Ciência e tecnologia para a cidadania" ou Adequação Sociotécnica com o Povo?}

\section{Introdução}

Este capítulo discute a forma como o tema da relação Ciência, Tecnologia e Sociedade vem sendo tratado em alguns ambientes dedicados à analise das políticas de C\&T e de Ensino Superior da América Latina. Ele se contrapõe à corrente que não vê que o modo como se orientam hoje essas políticas não contribui para a melhoria das condições de vida do conjunto da sociedade. Mas, também, a outras que, embora possam ser consideradas menos nocivas, são ainda assim simplistas e ingênuas. Isto é, as que entendem que o problema poderia ser equacionado mediante a "difusão dos frutos do progresso científico e tecnológico para a sociedade", ou a "apropriação do progresso tecnológico por parte da população", ou ainda aquela que propõe a "apropriação do conhecimento científico e tecnológico pelos cidadãos" para assim obter um maior "entendimento público da ciência" e uma maior "participação pública na ciência". O trabalho se baseia no que considera uma constatação: a de que o conhecimento científico e tecnológico tal como hoje existe não é capaz de promover um estilo de desenvolvimento alternativo que proporcione maior equidade econômica, justiça social, e sustentabilidade ambiental, sobretudo quando se tem o contexto latino-americano como foco analítico e propositivo. E ao contrapor, no seu título, as ideias de Ciência e Tecnologia para a Cidadania e Adequação Sociotécnica com o Povo, busca ressaltar a necessidade de que nosso potencial de geração de conhecimento seja orientado mediante um processo presidido por interesses e valores compatíveis com o conceito de Povo, e com a sua participação na produção do conhecimento.

Só dessa forma, argumenta-se, será possível materializar a proposta bem intencionada, mas ingênua - de colegas que levantam a bandeira da "Ciência e Tecnologia para a Cidadania". 
A seção que segue parte da percepção de que o conceito Cidadania usado por esses colegas, associado à sua acepção marshaliana (Marshall, 1967), não é adequado à materialização da proposta que defendem. Percepção baseada, entre outras coisas, no fato de que embora tenha sido a adotada pela social-democracia como balizamento para a construção do Estado do bem-estar, ela foi depois esvaziada pelo neoliberalismo, que também levou o próprio Estado ao descrédito e à inoperância. Por isso, partindo da distinção que fazem autores marxistas que analisam a relação Estado-Sociedade entre Cidadania, Nação e Povo no Estado capitalista, procura-se mostrar porque o processo de geração de conhecimento, que é o tema que se trata na quarta seção - Ciência e Tecnologia ou Adequação Sociotécnica? - deveria ter como alvo não a Cidadania, entendida como fundamento abstrato do Estado capitalista, ou a Nação, seu referencial, e sim o Povo, entendido como fundamento e referencial ambíguo deste Estado.

O objetivo da segunda seção pode então ser entendido como uma tentativa de explicitar mais claramente, tendo por base uma abordagem marxista, o sujeito-alvo da construção analítico-conceitual que venho desenvolvendo em torno da proposta de Adequação Sociotécnica (Dagnino, 2002; Dagnino...et al, 2004). Ao fazê-lo, dei-me conta, e espero que os leitores que acompanham meu esforço dedicado àquela construção concordem comigo, que precisar as diferenças entre aquelas três mediações pode torná-la mais inteligível e eficaz.

Entre a segunda e a quarta seções, foi inserida outra - A emergência do Povo como fundamento e referencial do Estado e os empreendimentos autogestionários? - que apresenta argumentos que me parecem suficientes para responder afirmativamente à pergunta que seu título formula.

\section{Cidadania, Nação e Povo na América Latina de hoje $\mathrm{e}^{10}$}

Nesta seção, busca-se uma aproximação da atualidade da América Latina para justificar o argumento de que a ação das forças progressistas dirigida ao aspecto cognitivo da construção de um estilo alternativo de desenvolvimento (o que tenho chamado de proposta da AST) deve ter o Povo como sujeito-alvo.

10 Esta seção segue muito de perto o conteúdo da segunda parte do trabalho de Guillermo, O’Donnell, “Anotações para uma Teoria do Estado”, cujo objetivo central é, justamente, esclarecer as diferenças entre os três conceitos. Ainda entre autores latino-americanos, serviram como referência o trabalho de Oscar Oszlak, Estado e Sociedade: Novas Regras do Jogo?. 
Inicio com uma referência ao fato de que, num mundo em que a guerra continua sendo o processo essencial da expansão capitalista, a América Latina, talvez pela sua pouca importância no cenário global, é a única região que se tem mantido à margem deste processo. $\mathrm{E}$ isso ao mesmo tempo em que os países da região (hoje conhecida como a mais desigual do planeta) estão se configurando como palco de uma quase generalizada "sublevação" de seus Povos. Eleições de líderes populares que se opõem ao modelo do neoliberalismo triunfante depois do fim da Guerra Fria, ou da derrubada de governantes que fogem às suas promessas de campanha e aderem a este modelo, mostram uma surpreendente convergência entre dois processos autônomos que vêm apresentando uma resultante favorável para as forças que anseiam por um estilo de desenvolvimento alternativo. A década neoliberal dos anos 1990 não cumpriu o que prometeu e provocou uma reação popular e eleitoral que varreu os governos conservadores, através de eleições de governos populares e democráticos, em quase todos os países da América Latina ${ }^{11}$.

Esse resultado é essencial para o argumento que desenvolvo em seguida. Por esta razão, volto um pouco no tempo, para entender como ele se tornou possível. Inicio por ressaltar que o Povo, a terceira das mediações entre o Estado e a Sociedade, embora esteja sempre presente em certo grau em qualquer Estado capitalista, teve maior importância nos casos latino-americanos, que no capitalismo central. O que é ao mesmo tempo causa explicativa e consequência do fenômeno do Populismo; cujo espectro, ao contrário do que se pensava quando do final do ciclo de regimes militares sul-americanos, continua rondando a América Latina.

A menor vigência entre nós da Cidadania como mediação efetiva entre Estado e sociedade pode também ser entendida como causa e consequência do papel mais importante que entre nós adquire o Povo. Ela parece se dever à menor extensão e densidade do capitalismo latino-americano, que não chegou a aperfeiçoar, como ocorreu nos países centrais, o conjunto de aparências abstratas do qual a Cidadania é um componente. $\mathrm{Na}$ verdade, os latino-americanos pobres, que em situações de crise são candidatos a constituir-se como Povo, sobretudo aqueles que nunca foram incorporados diretamente ao processo formal de exploração capitalista (que hoje representam mais da metade da população economicamente ativa da região) nunca foram, de fato, cidadãos.

11 É do trabalho de José Luis Fiori - O poder global e a nova geopolítica das nações - que tomei esta proposição. 
No que respeita a pouca importância relativa da solidariedade coletiva Nação, há que lembrar o fato dos países da América Latina terem apresentado um processo de constituição das bases de "seu" capitalismo bem distinto daquele que ocorreu nos países da Europa (e do Japão). Sem entrar em detalhes, e resumindo um longo e importante debate, quero apenas ressaltar uma característica distintiva dos dois processos. Naqueles países, o feudalismo foi sendo suplantado pelo capitalismo em meio a uma intensa luta entre grupos sociais que, de uma forma complexa, lenta e variada foram dando origem ao que vieram a ser as nacionalidades e a solidariedade coletiva Nação. $\mathrm{O}$ fato de que, ao contrário deles, os países da América Latina tiveram um Estado (implantado artificialmente pelos conquistadores) antes de terem uma Nação, pode ser tomado como síntese dessa ideia.

Passando agora para perceber o que ocorreu nos últimos decênios, e iniciando pelo plano endógeno, é forçoso reconhecer que a América Latina "capitalizou-se" ${ }^{12}$. Ela se tornou inteiramente capitalista, seja em termos estruturais, seja em termos superestruturais (como modo de produção, como hegemonia, como economia e como cultura). A "sociedade tradicional" continuou a existir, mas ao lado de outra moderna, de opulência seletiva. Uma sociedade high tech, das redes de comunicação, dos sistemas midiáticos sofisticados que submeteu funcional e ideologicamente e passou a modelar os valores da sociedade como um todo e que produz em seu seio um processo inaudito e generalizado, ainda que com características variadas de superexploração do trabalho.Todos os que nela "habitam", mesmo que nada ganhem com o capitalismo, mesmo que se relacionem com ele apenas na condição de marginalmente explorados (ou nem isto!), passaram a aceitar e cultuar esses valores.

No plano externo, a América Latina “globalizou-se". Ela não somente aprofundou sua inserção econômica subordinada no mercado mundial, como se tornou mais condicionada pelo que acontece no mundo: a mundialização das relações sociais, econômicas e políticas, a financeirização e transnacionalização das economias, a perda de soberania dos Estados nacionais, a desregulação dos mecanismos de financiamento do setor público etc.

12 Os parágrafos que seguem reproduzem quase literalmente as ideias expostas por Marco Aurélio Nogueira em seu trabalho "O pensamento político e a redemocratização do Brasil”, onde aparece esta expressão que alude a um também longo e importante debate ocorrido no seio da esquerda latino-americana a respeito da vigência do conceito de burguesia nacional. 
As dinâmicas associadas a esses dois planos engendram um processo caracterizado pela subalternidade e pela dependência em que a convivência entre aquelas duas "sociedades" recria a sua condição periférica. A subversão das formas tradicionais de vida e a fragmentação da sua sociabilidade não vêm associadas à inclusão e à dignidade social dos indivíduos como ocorreu no capitalismo avançado. Em vez do surgimento da Cidadania como mediação capitalista tout court se fortaleceram formas naturalizadas de desigualdade. Miséria, exclusão social, desemprego estrutural e marginalidade misturam-se com restos de latifúndios improdutivos e formas primitivas de exploração da mão de obra e com as dinâmicas "deslocalizadas" do mundo digital e transnacional.

A democratização política foi limitada e condicionada por esse processo. As instituições não foram capazes de responder ao descontentamento por ele gerado levando a que também os partidos e os sindicatos perdessem legitimidade. As pessoas votam, mas não se sentem representadas. Tentam converter em participativa uma democracia que é apenas representativa e lutam por seus direitos, mas não conseguem se afirmar como sujeitos de obrigações e deveres: há muitos direitos políticos formais e poucos direitos civis para a população pobre.

Esse quadro de estiolamento de uma Cidadania que na verdade nunca se constituiu de fato, não chegou a apagar a expectativa social de proteção e cobertura estatal por parte dos setores não inteiramente marginalizados e de uma classe média que, desvalorizada e confundida, tenta defender seus direitos perante o Estado neoliberal.

Governos de diferentes inclinações políticas foram se dando conta de que teriam que aceitar formas de gestão, em particular no plano das políticas sociais, mais participativas. Mas a movimentação social que, por essa via, poderia ter levado à recuperação das solidariedades coletivas de Cidadania e de Nação, ainda que num Estado "reformado" segundo a cartilha neoliberal, seguiu a tendência societal demarcada por aquelas duas dinâmicas. O fortalecimento da sociedade civil deu-se através da afirmação dos interesses particulares e não da construção de consensos, projetos coletivos ou novos arranjos de poder.

Se o fortalecimento da sociedade civil provocou um encolhimento do poder arbitrário do Estado que ajudou a democratização, o fato de isso ter ocorrido em simultâneo a uma perda de força e legitimidade da ação estatal levou a que a perspectiva de ruptura e de contestação que poderia levar a uma recuperação daquelas duas solidariedades coletivas não tenha se verificado. A contrapartida da desregulação do Estado no plano da sociedade foi a desorganização dos grandes agregados (as classes 
sociais) que serviam de referência objetiva para a política. À medida que se desfazia esse referencial de representação política, tornava-se mais aceitável a forma atomizada (quando não clientelista) pela qual o Estado "enxugado" passava a processar, junto a indivíduos, grupos e movimentos autorreferidos, as demandas sociais que caberia à Cidadania e à Nação conduzir.

O ciclo vicioso se completa com a progressiva deterioração da capacidade do Estado de exercer plenamente o monopólio do uso legítimo da força, de atuar como promotor do "bem comum", de continuar a elaborar políticas, tomar decisões, garantir e proteger direitos. Enfim, com a crescente incapacidade, por parte do Estado, de assegurar os direitos dos nacionais (Nação) e legitimar-se perante os cidadãos (Cidadania).

$\mathrm{Na}$ sociedade, cresce a incapacidade de utilização dos canais institucionais. Quanto menos política se tem (quanto menos projetos coletivos e valores socialmente referidos), maior a sensação de que o poder político não é necessário para representar os interesses das classes sociais. Ao passarem a ser veiculados por técnicos e especialistas, os interesses particulares diminuíram suas chances de se traduzir e organizar como interesse coletivo.

No que respeita aos partidos de esquerda, que eram depositários de uma expectativa de alteração neste quadro, o que se verifica é que quando conseguem ocupar uma parte do aparelho de Estado e alcançar a cota de poder que as eleições e o sistema democrático vigente lhes permitem, sua preocupação é menos a de tentar orientá-lo para novas prioridades e para atender aos interesses das classes subalternas do que para ampliar sua base de sustentação na direção de outros segmentos sociais. Enleados na carga inercial da reforma liberal, submetidos aos efeitos retardados da onda do "enxugamento do Estado" e amargando o despreparo anunciado dos seus quadros, seja "técnico" para fazer fazê-lo funcionar "eficientemente" segundo as regras herdadas, seja político para transformá-lo no sentido de torná-lo capaz de cumprir o seu projeto político, a tendência é que eles se tornem meros gestores de uma crise que ajudaram a criar, mas que não lhes corresponderia resolver. É flagrante a preocupação de muitos desses quadros em gerir recursos de poder e em maximizar seus próprios interesses eleitorais, deixando de agir para organizar novas hegemonias ou novos consensos e consentimentos.

O resultado que nos lega esse processo, em termos da dificuldade de recuperação das solidariedades coletivas da Cidadania e da Nação, parece contraditório com a oportunidade de levá-la a cabo aberta pela 
"sublevação" popular que levou à eleição de governos democráticos, em quase todos os países da América Latina. Se bem e é certo que essa situação gera um ambiente propício para que aquelas duas solidariedades venham a ser recompostas, não é menos certo que sua emergência não esteve associada à Cidadania ou à Nação ou a instituições a elas relacionadas, e sim ao movimento popular. E meu argumento é que parece ser no âmbito de uma organização e radicalização desse movimento que poderão ser criadas as condições para a recuperação das solidariedades coletivas.

A desmoralização e perda de legitimidade dessas duas mediações e a virtual ausência de condições para recuperá-las instauraram um ciclo vicioso de difícil interrupção endógena. Mas, como resultado do mesmo processo que gerou esse ciclo vicioso, existe um assenso do movimento popular que parece apontar para uma possibilidade de sua interrupção exógena. É provável, e esta é a ideia central desta segunda seção, que se encontre no seu aprofundamento a chance de lograr aquela recuperação.

De fato, em meio a esse contexto de despolitização, surgem de modo difuso e errático, formas de politização alternativas que apontam para a emergência de uma solidariedade coletiva latente - o Povo - que passa a ocupar o vácuo deixado pela perda vigente da Cidadania e da Nação como mediações legítimas entre Estado e Sociedade. Buscando se impor aos impasses da política tradicional, essas formas de politização alternativas que são usual e genericamente denominadas de movimentos populares, colocam-se como possibilidades de superação de muitos dos desafios que acima se apresentou.

\section{Os empreendimentos autogestionários e a emergência do Povo como fundamento e referencial do Estado latino-americano}

Esta seção tem como objetivo mostrar a plausibilidade daquilo que o seu título afirma. Ele se inicia destacando que os empreendimentos autogestionários ${ }^{13}$ de produção de bens e serviços parecem ser a "ponta de lança” mais radical, consequente e prometedora do conjunto a que acima me referi como formas de politização alternativas que se organizam em torno de uma solidariedade coletiva Povo.

Mas antes de justificar o porquê dos qualificativos que dei a eles, é conveniente caracterizá-los ainda que resumidamente.

13 Esse conceito é, para efeitos deste trabalho, equivalente ao de empreendimentos econômicos solidários, empresas em autogestão, empreendimentos com características autogestionárias, cooperativas de trabalhadores, cooperativas de resistência. 
As experiências latino-americanas nesse campo (ou no campo mais inclusivo do que se conhece no Brasil como Economia Solidária e em outros países latino-americanos como Economia Social) ganharam terreno a partir dos anos de 1990, numa conjuntura defensiva do movimento dos trabalhadores. De fato, as fábricas recuperadas, cooperativas e associações de trabalhadores surgiram na contramão do intenso processo de desestruturação e precarização do trabalho, cujo ritmo passou a ser cada vez mais ditado por aquelas dinâmicas que levaram a que a América Latina se "capitalizasse" e "globalizasse". Naquela conjuntura, algo que não era mais do que uma série de experiências isoladas ganha corpo, tendo como palco as unidades produtivas em crise, especialmente as empresas familiares falidas. Surge uma perspectiva nova que aponta para a possibilidade real da propriedade coletiva dos meios de produção. Além disso, e é importante destacar, essas experiências passaram a reivindicar para si (e a assumir) o sentido das bandeiras históricas do associativismo e da autogestão.

As iniciativas autogestionárias de produção remontam há pelo menos dois séculos. Neste percurso, apresentaram formas institucionais e de organização variadas e submetidas às condições materiais e sociais da ocasião. E tem sido, em momentos de ascensão do ciclo das lutas sociais que elas ganham força, e se projetam como possibilidade de superação das relações sociais e do modo de produção capitalistas. Seu princípio articulador associativista tem se mostrado capaz de assegurar, por um lado, o caráter orgânico da instituição operária e, por outro, a efetivação de laços de solidariedade com outros grupos sociais dos quais os trabalhadores eram também agentes ativos. Ele parecia "fundir", no seu início, duas funções que só posteriormente vieram a ser divididas: a organização para a produção dos meios de vida, especialmente através das diversas formas de cooperativismo (no início, principalmente, de produção, consumo e crédito) e para a resistência coletiva e política à implantação do capitalismo que passava a dominar todas as esferas da vida social. Ao substituírem a competição entre os trabalhadores pela solidariedade, e a fragmentação pelo coletivismo, essas formas associativas de produção revelaram um duplo aspecto de meio e de fim. A autogestão das suas lutas passa a ser vista pelos trabalhadores, então, como indissociável da autogestão da produção e da vida social (Faria, 2005).

Voltando à América Latina de hoje, em que a situação de crise se faz acompanhar com o fortalecimento da autogestão, é necessário avaliar em que medida elas serão capazes de, recuperando o papel alavancador daquelas duas funções, servir de polo de aglutinação de forças que 
operacionalize, por aquelas duas vias, uma transformação efetiva das relações sociais de produção capitalistas.

Essa avaliação, entretanto, remete ao início desta seção, quando classifiquei os empreendimentos autogestionários como a "ponta de lança" mais radical, consequente e prometedora das formas de politização capazes de impulsionar a adoção de um estilo de desenvolvimento alternativo.

Ela é a mais radical (no sentido etimológico original, de ir à raiz da questão) porque questiona o cerne do sistema capitalista, sua estrutura econômico-produtiva. Por produzirem bens e serviços através de um tipo de organização do processo de trabalho, propriedade dos meios de produção, repartição do excedente gerado, mecanismos de absorção de mão de obra, canais de aquisição de insumos e comercialização dos produtos etc., distinto daquele das empresas capitalistas, e por terem certa independência em relação ao mercado formal, os empreendimentos autogestionários representam uma ameaça, claro que ainda latente (como em seguida se aborda), ao funcionamento dessa estrutura econômico-produtiva. Por oferecerem aos segmentos mais pobres da população uma alternativa ao consumismo exacerbado e ao obsoletismo planejado que cada vez mais caracteriza essa estrutura, eles tocam o seu ponto mais sensível, nevrálgico: aquele relacionado à possibilidade de uma crise de subconsumo.

Ela é a "ponta de lança" mais consequente porque é capaz de materializar a crítica que fazem essas formas de politização emergentes à maneira como os detentores do poder econômico e político vêm penalizando os segmentos mais pobres em ações que se contrapõem à exclusão social. De fato, ao proporcionarem a criação de oportunidades de trabalho e renda numa economia que cresce sem gerar emprego, os empreendimentos autogestionários não apenas oferecem uma possibilidade de inclusão social como indicam aos excluídos a forma como, através da sua ação solidária, é possível construir alternativas ao circuito formal, controlado pelo capital. À medida que redes de Economia Solidária comecem a se constituir como cadeias de agregação de valor autônomas e que formas tecnológicas adequadas permitam conferir a elas a "competitividade" necessária para assegurar sua sustentabilidade, aumentará a sua consequência. À medida, também, que se acumulem experiências (bem e mal-sucedidas) de implantação de empreendimentos autogestionários, aumentará a sua coerência. Será possível orientar os vários níveis dos governos que hoje aplicam um volume significativo de recursos no momento compensatório dos programas sociais a melhor implementarem os outros dois momentos: formativo e "empreendedor". Existe, de fato, uma grande ignorância a respeito de que tipo de formação deve ser 
oferecida aos excluídos para que adquiram as competências necessárias para constituírem os empreendimentos autogestionários. Ignorância que alimenta a situação contraditória e lamentável de que esses governos sigam gastando com um ensino profissional que prepara para o trabalho na empresa privada, e embora tenha granjeado a aprovação dos sindicatos, quando havia possibilidade de emprego e ascensão social, apresenta-se hoje como disfuncional para os interesses das classes subalternas.

Finalmente, considero os empreendimentos autogestionários como a forma mais prometedora porque, por terem seu fundamento no associativismo e na autogestão, elementos cruciais da trajetória de constituição da identidade e autonomia da classe trabalhadora e dos movimentos populares que junto a ela se organizaram ao longo da história, eles são capazes de cumprir um papel singular no processo que atualmente se inicia na América Latina. O papel de combinar dois processos que o capital conseguiu separar e que nem as experiências de socialismo que tivemos lograram juntar: a organização da produção e das lutas dos trabalhadores sob o único e prometedor princípio da autonomia e da solidariedade.

Apesar de possuírem esses atributos e, provavelmente, por causa deles, os empreendimentos autogestionários (cooperativas, fábricas recuperadas, empreendimentos de agricultura familiar etc.) enfrentam sérios obstáculos para a sua implantação e sobrevivência. Entre eles, destacarei aqui aquele que tem relação direta com o plano cognitivo que é o que me interessa analisar: o da sustentabilidade num mercado onde atuam empresas capitalistas com acesso privilegiado a conhecimentos capazes de alavancar sua competitividade em relação a eles ${ }^{14}$.

As imposições do Estado em relação à compra de produtos e à contratação de serviços, e as práticas adotadas em relação à concessão de crédito etc., também prejudicam a sustentabilidade econômica dos empreendimentos e dificultam a alteração da divisão do trabalho capitalista. $\mathrm{O}$ mesmo ocorre em relação ao estímulo à aquisição de uma TC (embutida ou não em máquinas, equipamentos e insumos produtivos) inadequada aos empreendimentos autogestionários. Dessa forma, mesmo quando ocupado por governos simpáticos aos empreendimentos autogestionários, o Estado os prejudica e favorece as empresas privadas e

14 Do que hoje se gasta em pesquisa no mundo, $70 \%$ são gastos empresariais (e deste, $70 \%$ são de transnacionais, isto é, $50 \%$ do total). Os 30\% restantes que correspondem ao gasto público, como é evidente, também se orientam direta ou indiretamente para a mesma finalidade. O que faz com que estimativas realizadas pela professora Amy Smith do MIT Massachusetts Institute of Technology -- apontem que "quase 90\% dos dólares de P\&D são gastos na criação de tecnologias que atendem aos $10 \%$ da população mais rica do mundo". 
grandes. No plano técnico-administrativo interno aos empreendimentos, essas imposições dificultam a orientação autogestionária em função da tendência à sua acomodação às normas e formas usuais previstas nos manuais e reconhecidas institucionalmente. Práticas e recomendações distópicas e contraproducentes, como a de que esses empreendimentos devem elaborar um "plano de negócio", esperar benefícios oriundos da "responsabilidade social empresarial", capacitar seus dirigentes segundo os moldes do business administration e do planejamento corporativo, são frequentemente adotadas, muitas vezes, com a melhor das intenções, por ONGs e órgãos públicos.

O que se observa, como regra, é um isolamento entre esses empreendimentos e a não constituição de encadeamentos produtivos para frente ou para trás que permitam um apartamento das relações com o mercado. Ou, pelo menos, um "retardamento" de sua captura pelas cadeias produtivas dominadas pelo capital. Tudo isso faz com que, frequentemente, o subsídio governamental especificamente destinado a esses empreendimentos (com os de catadores de material reciclável), ou proporcionado aos excluídos, mediante os programas compensatórios que visam à "inclusão social", seja apropriado como trabalho não pago pelos "atravessadores". Ele é repassado parcialmente aos que controlam o circuito formal de geração e apropriação de excedente da economia através da compra de matérias-primas (às vezes, nobres) e produtos escassamente elaborados. Caso eles tivessem os encargos sociais e o salário que a legislação prevê incorporado aos seus preços, sua aquisição não seria atrativa.Aliás, é preciso lembrar que as áreas onde se localizam esses empreendimentos só não são ocupadas pelas empresas privadas porque sua taxa de lucro se situa bem abaixo da média da economia. É sua baixa rentabilidade que torna essas áreas passíveis de serem exploradas por esses empreendimentos.

Essa situação adversa que sujeita os empreendimentos autogestionários aos limites da tecnologia capitalista (e do Estado que a reforça) não é percebida como tal pelos quadros técnico-políticos da esquerda. Eles tendem a pensar que a apropriação coletiva dos meios de produção pelos trabalhadores, a modificação das relações de propriedade, garante por si só (isto é, sem um reprojetamento da tecnologia existente) a adoção de formas autogestionárias de organização da produção, comercialização e consumo pelos trabalhadores. E que elas poderiam assim assumir características sociais, solidárias ou, até, socialistas.

O debate que se inicia, quando há um questionamento dessa visão, tende a ser"encerrado" com a recomendação de que os empreendimentos 
autogestionários devem "modernizar-se" incorporando as novas tecnologias capazes de torná-los "competitivos". A visão, à qual me filio, e que se contrapõe à da maioria dos partidários da Economia Solidária, considera que ainda que isso fosse possível não seria desejável, uma vez que colocaria em risco suas premissas e terminaria fazendo com que eles, caso bem sucedidos, pouco viessem a diferir das empresas privadas. Essa visão acredita que a TC, engendrada sob a égide das relações sociais de produção capitalistas para atender à lógica de acumulação das suas grandes empresas, não pode ser "usada" sem significativas modificações nos empreendimentos autogestionários. E, por extensão, para construir um estilo de desenvolvimento alternativo.

O máximo que chegam a vislumbrar os partidários da visão ainda dominante é que deveria haver uma preocupação em adaptar a organização capitalista do processo de trabalho (orgware) ao caráter autogestionário dos empreendimentos. Por entenderem a tecnologia hardware (máquinas, equipamentos, insumos de produção etc.) como simples artefatos neutros em relação ao uso que deles se possa fazer, não percebem a inadequação que se coloca no centro da visão alternativa, que se designa em seguida como proposta da Adequação Sociotécnica.

A próxima seção é dedicada a detalhar a proposta da AST. Mas antes de fazê-la, e para facilitar o seu entendimento, é conveniente situá-la frente a outras três concepções a respeito da questão que ela aborda. Em particular em relação às duas primeiras - Instrumentalismo e Determinismo - que parecem ser o substrato em que se apoiam os partidários da visão ainda dominante. É o que se faz no primeiro item da próxima seção.

\section{Ciência e Tecnologia ou Adequação Sociotécnica?}

Depois de mostrar porque a solidariedade coletiva Povo parece ser a mais adequada para levar à frente a construção de um estilo de desenvolvimento alternativo, na América Latina, e porque, dentre as formas de organização popular mais eficazes nesse sentido, os empreendimentos autogestionários ocupam um papel central, apresento, nesta seção, um conteúdo que tenho explorado em outros trabalhos e, por isso, talvez já seja conhecido pelo leitor. Sua inserção aqui cumpre o objetivo de aprofundar a avaliação acerca dos obstáculos cognitivos que os empreendimentos autogestionários devem enfrentar para sua consolidação, explorando as concepções existentes sobre a Tecnociência e as possibilidades de sua superação pela via da proposta da AST. 


\section{As quatro concepções sobre a Tecnociência}

Uma maneira simples de introduzir a ideia da AST é situá-la no âmbito das perspectivas (ou concepções) que se expressam em nossa sociedade sobre a tecnociência, conceito que parece mais apropriado do que o de "Ciência e Tecnologia" para abordar o tema deste trabalho ${ }^{15}$.

No esquema que segue, estão representadas essas concepções em cada um dos quadrantes delimitados pelos eixos da Neutralidade (vertical) e do Determinismo (horizontal).

\begin{tabular}{|c|c|}
\hline \multicolumn{2}{|c|}{ NEUTRA } \\
\hline $\begin{array}{l}\text { DETERMINISMO } \\
\text { otimismo da visão Marxista } \\
\text { ortodoxa: força produtiva que, no } \\
\text { longo prazo, empurra } \\
\text { inexoravelmente a modos de } \\
\text { produção mais perfeitos }\end{array}$ & $\begin{array}{l}\text { INSTRUMENTALISMO } \\
\text { visão moderna padrão = fé liberal, } \\
\text { otimista no progresso: } \\
\text { conhecimento verdadeiro e } \\
\text { eficiente do mundo natural a } \\
\text { serviço de qualquer projeto }\end{array}$ \\
\hline 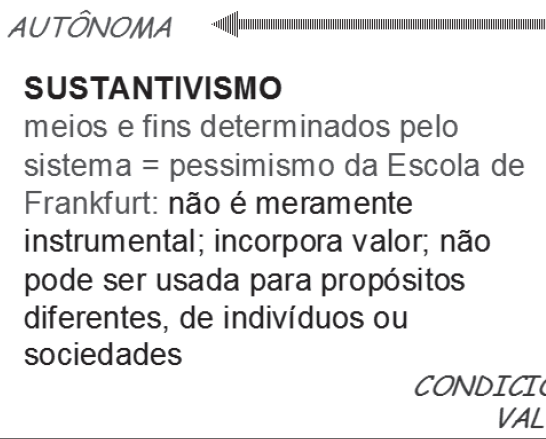 & $\begin{array}{l}\text { Adequação Sociotécnica } \\
\text { opção engajada = ambivalência e } \\
\text { resignação: reconhece o } \\
\text { substantivismo, mas é otimista; vê } \\
\text { graus de liberdade; internalizar } \\
\text { valores alternativos ex ante na } \\
\text { produção } \\
\text { IADA POR } \\
\text { IES }\end{array}$ \\
\hline
\end{tabular}

15 Segundo Núñez (2000), "La ciencia y la moderna tecnología son inseparables; en consecuencia han llegado a ser actividades casi indistinguibles, y si la Revolución Científica del Siglo XVII, y la Revolución Industrial iniciada en el Siglo XVIII fueron procesos relativamente independientes, la fecundación recíproca y sistemática entre ciencia y tecnología es, sobre todo, un fenómeno que se materializa a partir de la segunda mitad del siglo XX y se acentúa notablemente en el siglo actual. Por eso, es difícil saber a que se dedican las personas que trabajan en un laboratorio de I+D de una gran industria: ¿hacen ciencia o hacen tecnología? Quizás simplemente hagan "tecnociencia", actividad donde los viejos límites son desdibujados". E segue, "La imagen de la ciencia como una actividad de individuos aislados que buscan la verdad sin otros intereses que los cognitivos no coincide con la realidad social de la ciencia contemporánea; la CyT ha sido impulsada por la búsqueda de hegemonía mundial de las grandes potencias y a las exigencias del desarrollo industrial y las pautas de consumo que se producen y se difunden desde las sociedades que lideran los procesos de modernización". 
No eixo vertical, representa-se, na parte superior, a perspectiva que considera a tecnociência como neutra. Isto é, livre dos valores (e interesses) econômicos, políticos, sociais ou morais (de raça, etnia, gênero etc.) dominantes no ambiente em que ela é produzida. O qual pode ser entendido, dependendo da perspectiva que a análise de uma situação qualquer demandar, de modo abrangente e mais abstrato, como uma determinada formação histórico-social ou regime de acumulação, ou de maneira mais específica e concreta, como um dado país, âmbito disciplinar, ou contexto profissional (laboratório de pesquisa universitária, centro de P\&D de uma empresa transnacional etc.). Na parte inferior, representa-se a perspectiva que entende a tecnociência como condicionada por esses valores.

Segundo a perspectiva neutra, o resultado material da tecnociência, um dispositivo técnico qualquer, é simplesmente uma concatenação de mecanismos causais. O qual como qualquer outra forma de conhecimento, aplicado ou não, "pode ser usado para o bem ou para o mal". Para a perspectiva que entende a tecnociência como condicionada por valores, esse resultado material, enquanto entidade social (socialmente construída), tem um modo especial de carregar valores em si próprio e a reforçá-los.

O eixo horizontal permite situar as perspectivas a respeito do elemento do "determinismo tecnológico" da tecnociência. Nele se representa, à esquerda, a perspectiva que considera a tecnociência como autônoma e, à direita, a que a entende como passível de ser controlada pelo Homem. De acordo com a primeira, a tecnociência, no seu aspecto eminentemente científico, e apoiada no método científico, conduziria um Homem infinitamente curioso em contato com uma natureza infinitamente bela, à verdade. E, no seu aspecto técnico (ou tecnológico) na direção da maximização da eficiência (entendida esta como um conceito primitivo que não admite a pergunta "eficiência para quem?"). Ela teria suas próprias leis imanentes, seguiria uma trajetória linear e inexorável, governada por esse impulso endógeno. Caberia à sociedade, submetida a este poder de determinação da tecnociência - ou a este "determinismo tecnológico" - aceitar seus impactos e tentar tirar dela o melhor proveito. De acordo com a segunda perspectiva, a sociedade ou os grupos sociais estariam em condições de decidir em cada momento os rumos que irá seguir a tecnociência e, como se discutirá em seguida, a forma como ela poderá ser reprojetada; e não apenas a maneira como poderá ser aplicada. Dependeria dessas decisões as características que assumiriam os sistemas técnicos que crescentemente condicionam a sociedade. 


\section{As quatro concepções sobre a Tecnociência}

A primeira dessas quatro concepções, que combina as perspectivas do controle humano da tecnociência e da neutralidade de valores, é o Instrumentalismo. Apesar de ser herdeira do iluminismo e do positivismo, ela expressa uma percepção contemporânea que concebe a tecnociência como uma ferramenta gerada pela espécie humana (em abstrato e sem qualquer especificação histórica ou que diferencie os interesses de distintos segmentos sociais) através de métodos que, ao serem aplicados à natureza, assegurariam à ciência atributos de verdade e à tecnologia, de eficiência. Dado que pode atuar sob qualquer perspectiva de valor, o que garante o seu uso "para o bem" é algo estranho ao mundo do conhecimento científico-tecnológico e dos que o produzem: a "Ética"16. Só se esta não for respeitada pela sociedade, esse conhecimento poderá ter implicações indesejáveis.

O Instrumentalismo aceita a possibilidade de um controle externo e ex-post ou a posteriori da tecnociência. Depois de produzida através das atividades realizadas em organizações públicas (universidades, institutos de pesquisa) e privadas (empresas, centros de P\&D), ela poderia ser submetida a um controle social efetivo baseado num conjunto de princípios éticos de tipo moral, social, ambiental, étnico, de gênero, reconhecido como positivo. Seria esse conjunto de valores o que asseguraria que a utilização do conhecimento ocorresse de modo com eles coerente, de um modo ético.

A segunda concepção - do Determinismo - que combina autonomia e neutralidade é a associada à visão marxista tradicional. Simplificando, ela nos diria que: a tecnociência é um motor, uma força produtiva que empurra inexoravelmente as relações sociais de produção na direção de modos de produção cada vez mais perfeitos - do escravismo para o feudalismo, deste para o capitalismo, e do capitalismo para o socialismo e o comunismo.

$16 \mathrm{Um}$ dos eventos que mais marcou as discussões a esse respeito foi o desenvolvimento da tecnologia nucelar e da pesquisa científica que tornou possível o lançamento das bombas atômicas sobre Hiroshima e Nagasaki. Neste caso, os cientistas que colaboraram no projeto Manhattan e que, inclusive, convenceram os líderes militares de sua necessidade ou conveniência, não podiam alegar que o conhecimento que produziam poderia ser "usado para o mal". Mesmo porque, na sua visão, o "bem" de derrotar o nazismo justificaria o "mal" de aniquilar civis. No período que se seguiu, cada vez que uma aplicação da tecnologia nuclear (na saúde, na produção de alimentos etc) era lograda, ou que um desenvolvimento tecnológico militar era usado no setor civil, fortalecia-se a ideia de que o eticamente problemático era o uso do conhecimento. 
Essa concepção está impregnada na esquerda, inclusive na latino-americana. A ideia é de que a tecnociência é neutra e inerentemente boa, e que hoje ela é utilizada para servir a um modo de produção que está baseado na exploração do homem pelo homem, mas amanhã, quando puder ser usada para outro projeto político, quando for apropriada pela classe trabalhadora, construirá o socialismo (ou o estilo de desenvolvimento alternativo).

A primeira e a segunda concepções aceitam a neutralidade, mas, no primeiro caso, não se pretende alterar as relações sociais e os modos de produção, segue vigente o capitalismo. E seria a ética e não algo intrínseco ao conhecimento que teria a responsabilidade de fazer com que o capitalismo seja mais ou menos desempregador; se gerará o aquecimento global ou não. No segundo, essa responsabilidade está condicionada a uma mudança social impulsionada pela classe trabalhadora. E é interessante observar que o marxismo tem uma capacidade muito aguda de diagnosticar como o conhecimento tem servido para a extração da mais-valia e para a opressão dessa classe. Mas, ao mesmo tempo, aceita que a simples aparição de condições subjetivas e objetivas que permitam a mudança na correlação de forças na sociedade dando à classe trabalhadora o acesso ao poder seria suficiente para impulsionar a transição do capitalismo ao socialismo. Isto é, que aquele mesmo conhecimento (sem qualquer solução de continuidade no plano cognitivo) serviria para a construção de um modo de produção distinto.

A terceira concepção - do Substantivismo - entende a tecnociência como dotada de autonomia e intrinsecamente portadora de valores. Seus partidários compartilham o conteúdo mais abrangente da crítica ao marxismo tradicional formulada pela Escola de Frankfurt a partir da década de 1960 e a particularizam em relação à questão da tecnociência (ou da tecnologia) da seguinte forma. Enquanto a ideia de neutralidade do Instrumentalismo atribui à tecnociência a busca de uma eficiência (abstrata, mas substantiva), a qual pode servir a qualquer concepção acerca do modo ideal de existência humana, o compromisso da tecnociência com o regime de acumulação capitalista dominante (que embora pareça natural e único, é ideologicamente sustentado), faria com que os valores a ele inerentes fossem a ela incorporados. A tecnociência seria, então, substantiva e, intrinsecamente, capitalista.

Em consequência, não poderia ser usada para viabilizar propósitos de indivíduos ou sociedades que patrocinem outros valores. Carregaria consigo valores que têm o mesmo caráter exclusivo das religiões que estipulam as crenças, orientam a conduta e conformam ideologicamente 
o inconsciente coletivo de grupos sociais. A tecnociência capitalista tenderia inevitavelmente a se afinar com os valores imanentes da "sociedade tecnológica", como a eficiência, o controle e o poder.Valores divergentes - alternativos - não conseguiriam com ela conviver e, seu poder de determinação seria tamanho que eles não poderiam prosperar ou mesmo sobreviver num ambiente como o que a tecnociência tende cada vez mais a conformar na sociedade contemporânea.

O Substantivismo (radical e pessimista) se diferencia do Determinismo. Este, ao aceitar que a tecnociência, por não ser portadora de valores, é o servo neutro de qualquer projeto social, idealiza um final sempre feliz para a história da espécie. Também otimista é a visão moderna tradicional padrão do Instrumentalismo. Ao entender a tecnociência como uma simples ferramenta que incorpora um conhecimento verdadeiro e eficiente acerca do mundo natural, mediante a aplicação de princípios éticos chegaremos a satisfazer todas as necessidades sociais, ele professa uma fé liberal no progresso.

A quarta concepção é a da Adequação Sociotécnica (AST). Ela combina as perspectivas da tecnociência como humanamente controlável e como portadora de valores. Seus partidários concordam com o Instrumentalismo (a tecnociência é controlável), mas reconhecem, como o faz o Substantivismo, que os valores capitalistas conferem à tecnociência características específicas, que os reproduzem e reforçam, que implicam consequências sociais e ambientalmente catastróficas, e que inibem a mudança social. Mas, ainda assim, veem na tecnociência uma promessa de liberdade. O problema não estaria no conhecimento como tal, mas no pouco êxito que temos tido até o momento em criar formas institucionais que, explorando a ambivalência (graus de liberdade) que possui o processo de concepção de sistemas tecnológicos e resignando-nos a "não jogar a criança com a água do banho", sejamos capazes de exercer o controle humano - coletivo e socialmente equânime - sobre ela.

A tecnociência não é percebida como uma ferramenta capaz de ser usada para qualquer projeto político ou em qualquer regime social de acumulação como pensam, otimisticamente, os partidários do Determinismo. Nem como algo que deve ser usado e orientado pela "Ética", como ingênua ou cinicamente querem os Instrumentalistas. Tampouco como um apêndice indissociável de valores e estilos de vida particulares, privilegiados em função de uma escolha (ou imposição) feita na sociedade, como os Substantivistas. Segundo eles, desde que "reprojetada" segundo critérios alternativos com características democráticas, e tendo seus objetivos subvertidos, como aconteceu com os programas de pesquisa sobre 
AIDS que não atendiam o interesse dos usuários ou com a rede centralizada que deu origem à Internet, ela pode servir como suporte para estilos de vida alternativos.

Apesar de as sociedades modernas sempre visarem à eficiência naqueles domínios em que aplicam suas capacidades e habilidades cognitivas (a tecnociência), afirmar que tais domínios não podem compreender nenhum outro valor significativo além da eficiência (capitalista), como proporia o Substantivismo, é negligenciar o poder de influência que possuem os grupos sociais para orientar a tecnociência. O que abre um amplo espectro de possibilidades para pensar esse tipo de escolhas, questioná-las, e submeter sua tradução tecnocientífica em projetos e desenvolvimentos a controles mais democráticos.

\section{A proposta da Adequação Sociotécnica}

Tributária das contribuições desenvolvidas por muitos autores e movimentos, dentre os quais, o que ficou conhecido como o da Tecnologia Apropriada e das críticas que a ele foram formuladas, a proposta da AST pretende aportar uma dimensão processual, uma visão ideológica e um elemento de operacionalidade delas derivadas.

A proposta da AST busca transcender a visão estática e normativa, de produto já idealizado, e introduzir a ideia de que a tecnociência (ou segundo os sociólogos da ciência hoje mais influentes, a ciência; e segundo os da tecnologia, a tecnologia) é em si mesma um processo de construção social e, portanto, político (e não apenas um produto) que terá que ser operacionalizado nas condições dadas pelo ambiente específico onde irá ocorrer, e cuja cena final depende dessas condições e da interação passível de ser lograda entre os atores envolvidos.

A necessidade de criar um substrato cognitivo-tecnológico a partir do qual atividades não inseridas no circuito formal da economia poderão ganhar sustentabilidade e espaço crescente em relação às empresas convencionais é uma das origens do conceito da AST.

A AST pode ser concebida por semelhança ao processo - denominado por alguns de Processo de Aprendizado e por outros de Tropicalização - extensivamente abordado na literatura latino-americana (e posteriormente, mundial) sobre Economia da Tecnologia, desde os anos de 1960, de adaptação da tecnologia proveniente dos países centrais às nossas condições técnico-econômicas (preço relativo dos fatores capital e trabalho; disponibilidade de matérias-primas, peças de reposição e mão de obra qualificada; tamanho, capacidade aquisitiva, 
nível de exigência dos mercados; condições edafo-climáticas etc) (Katz; Cibotti, 1976).

Nesse sentido, a AST pode ser entendida como um processo que busca promover uma adequação do conhecimento científico e tecnológico (esteja ele já incorporado em equipamentos, insumos e formas de organização da produção, ou ainda sob a forma intangível e mesmo tácita), não apenas aos requisitos e finalidades de caráter técnico-econômico, como até agora tem sido o usual, mas ao conjunto de aspectos de natureza socioeconômica e ambiental que constituem a relação Ciência, Tecnologia e Sociedade.

No contexto da preocupação com os empreendimentos autogestionários, a AST teria então por objetivo adequar a tecnologia convencional da empresa capitalista (e, inclusive, conceber alternativas) aplicando critérios suplementares aos técnico-econômicos usuais a processos de produção e circulação de bens e serviços em circuitos não formais, situados em áreas rurais e urbanas visando a otimizar suas implicações.

Dentre os critérios que conformariam o novo código sociotécnico (alternativo ao código técnico-econômico convencional), a partir do qual a tecnologia convencional seria desconstruída e reprojetada dando origem a processos de AST, pode-se destacar, além daqueles presentes no movimento da Tecnologia Apropriada, a participação democrática no processo de trabalho, o atendimento a requisitos relativos ao meio-ambiente (através, por exemplo, do aumento da vida útil das máquinas e equipamentos), à saúde dos trabalhadores e dos consumidores e à sua capacitação autogestionária.

O conceito de AST pode ser entendido com o concurso do diferencial proporcionado pelo construtivismo. Segundo esse enfoque, Construção Sociotécnica é o processo mediante o qual artefatos tecnológicos vão tendo suas características definidas através de uma negociação entre "grupos sociais relevantes", com preferências e interesses diferentes, no qual critérios de natureza distinta, inclusive técnicos, vão sendo empregados até chegar a uma situação de "estabilização" e "fechamento" (Bijker, 1995).

Nesse sentido, a AST pode ser entendida como um processo "inverso" - de caráter não apenas normativo, mas contra-hegemônico - ao da construção sociotécnica, cujo objetivo é descrever processos que têm ocorrido em ambientes onde os interesses e valores predominantes e não questionados são os do capitalismo. Nesse processo, um artefato tecnológico ou, mais genericamente, a tecnociência sofreria um processo de 
adequação a interesses políticos de "grupos sociais relevantes" distintos daqueles que o originaram. Assim definido, como um processo, e não como um resultado (uma tecnologia desincorporada ou incorporada em algum artefato) ou um insumo, o conceito permite abarcar uma multiplicidade de situações: o que denomino a seguir de "modalidades" de AST.

\section{As modalidades de Adequação Sociotécnica}

Buscando operacionalizar o conceito de AST, julgou-se conveniente definir modalidades de AST. O número escolhido (sete) não é arbitrário e poderia ser maior:

1) Uso: $O$ simples uso da tecnologia (máquinas, equipamentos, formas de organização do processo de trabalho etc.) antes empregada (no caso de cooperativas que sucederam a empresas falidas), ou a adoção de tecnologia convencional, com a condição de que se altere a forma como se reparte o excedente gerado, pode desencadear mudanças cognitivas no âmbito dos trabalhadores.

2) Apropriação: entendida como um processo que tem como condição a propriedade coletiva dos meios de produção (máquinas, equipamentos), ela implica em uma ampliação do conhecimento, por parte do trabalhador, dos aspectos produtivos (fases de produção, cadeia produtiva etc.), gerenciais e de concepção dos produtos e processos, sem que exista qualquer modificação no uso concreto que deles se faz.

3) Revitalização ou Repotenciamento das máquinas e equipamentos: significa não só o aumento da vida útil das máquinas e equipamentos, mas também ajustes, recondicionamento e a revitalização do maquinário. Supõe ainda a fertilização das tecnologias 'antigas' com componentes novos.

4) Ajuste do processo de trabalho: implica a adaptação da organização do processo trabalho à forma de propriedade coletiva dos meios de produção (pré-existentes ou convencionais), o questionamento da divisão técnica do trabalho e a adoção progressiva do controle operário (autogestão).

5) Alternativas tecnológicas: implica a percepção de que as modalidades anteriores, inclusive a do Ajuste do processo de trabalho, não são suficientes para dar conta das demandas por AST dos empreendimentos autogestionários, sendo necessário o emprego 
de tecnologias alternativas à convencional. A atividade decorrente desta modalidade é a busca e seleção de tecnologias existentes.

6) Incorporação de conhecimento científico-tecnológico existente: resulta do esgotamento do processo sistemático de busca de tecnologias alternativas e na percepção de que é necessária a incorporação à produção de conhecimento científico-tecnológico existente (intangível, não embutido nos meios de produção), ou o desenvolvimento, a partir dele, de novos processos produtivos ou meios de produção, para satisfazer as demandas por AST. Atividades associadas a esta modalidade são processos de inovação de tipo incremental, isolados ou em conjunto com centros de $\mathrm{P} \& \mathrm{D}$ ou universidades.

7) Incorporação de conhecimento científico-tecnológico novo: resulta do esgotamento do processo de inovação incremental em função da inexistência de conhecimento suscetível de ser incorporado a processos ou meios de produção para atender às demandas por AST. Atividades associadas a esta modalidade são processos de inovação de tipo radical que tendem a demandar o concurso de centros de P\&D ou universidades e que implicam na exploração da fronteira do conhecimento.

\section{Considerações Finais}

Meu objetivo, neste trabalho, foi mostrar que a bandeira da "Ciência e tecnologia para a cidadania" por não ser suficiente para que aqueles colegas que a levantam para assim contribuir, no plano do conhecimento, para a adoção de um estilo de desenvolvimento alternativo exige que o conhecimento existente seja objeto de uma Adequação Sociotécnica para que, com a participação do Povo como sujeito deste processo, ele possa atender aos seus valores e interesses. O objetivo foi perseguido através de quatro passos. Eles são apresentados aqui e não na Introdução porque se considerou que é possível, a esta altura, ter uma visão mais clara de sua pertinência.

O primeiro passo foi mostrar que, a recuperação da Cidadania e, também, da solidariedade coletiva Nação, submetidas a um ciclo vicioso de deterioração, demanda, no momento, pelo qual passam muitos países da América Latina, de um processo de organização e radicalização dos movimentos populares. Embora de enunciado simples, este passo demandou um longo percurso expositivo que começou por entender o Estado 
como um "mecanismo" de organização do consenso que conforma solidariedades coletivas a ele externas, orientadas a ocultar as rupturas da sociedade e seus vieses sistemáticos através de instituições cuja legitimação supõe mediações Estado-sociedade (fundamento e referencial) generalizadamente verossímeis. E que conduziu à ideia de que o Estado Capitalista para ocultar seu papel de mantenedor e reprodutor da sociedade capitalista deve sustentar uma ideologia de igualdade abstrata, no fundamento da Cidadania; concreta, porém indiferenciada, no referencial da Nação, e eventualmente, mais concreta e menos indiferenciada, no âmbito do Povo.

O segundo passo foi argumentar que dentre as formas de politização alternativas genericamente denominadas de movimentos populares, que estão surgindo em meio ao contexto de despolitização vigente, os empreendimentos autogestionários ocupam um papel central. Devido ao seu potencial alavancador do associativismo e da autogestão, elementos cruciais para a implantação de cadeias de produção e consumo alternativas aos circuitos do capital e para a organização da vida social e das lutas dos trabalhadores, eles podem ser um polo de aglutinação de forças que promova a adoção de um estilo alternativo de desenvolvimento.

O terceiro passo foi mostrar que, dentre os obstáculos para lograr que os empreendimentos autogestionários possam dispor do conhecimento necessário para a sua sustentabilidade frente às empresas privadas, existe um crucial e de natureza imaterial cuja remoção depende da substituição das concepções Instrumental e Determinista da tecnociência pela da Adequação Sociotécnica.

O quarto foi apresentar a postura da Adequação Sociotécnica indicando como ela pode ajudar no reprojetamento da tecnociência e na geração de alternativas cognitivas mais aderentes aos valores e interesses do Povo.

Por buscar interlocução com a corrente principal do marxismo, que ainda acredita que as "forças produtivas" seguem um caminho linear e inexorável e que podem ser "usadas" para outros fins caso sejam "apropriadas" pelos trabalhadores, a AST oferece um guia para a desconstrução/ reconstrução de artefatos tecnológicos adequados aos empreendimentos autogestionários. De fato, por reconhecer que estes demandam um conhecimento coerente com seus princípios, valores, interesses e objetivos e por estar baseada nos estudos sobre aprendizagem técnico-econômica latino-americanos e na visão de autores marxistas contemporâneos que revisitando os enfoques da construção social ciência e da tecnologia, argumentam no sentido contrário às concepções da neutralidade de 
ciência e do determinismo tecnológico, a proposta da AST oferece um instrumental útil para a análise e proposição de alternativas à tecnologia concebida e aplicada pela e para a empresa capitalista

Numa dimensão situada no nível da policy, a proposta da AST pretende ser um chamamento aos colegas interessados na construção de um estilo alternativo de desenvolvimento para que busquem perceber e atender as demandas cognitivas que ele coloca. Para que passem a questionar a ideia de que a solução para a exclusão social se dará no terreno puramente político; de que não existe um componente tecnológico (e mesmo científico) a ser satisfeito. E para que entendam que cabe a eles, enquanto parte da comunidade de pesquisa, participar junto aos movimentos populares no processo de AST. E, ao fazê-lo, contribuir para a emergência, no interior da comunidade de pesquisa, de um segmento capaz de incorporar as demandas cognitivas dos movimentos sociais à sua agenda de pesquisa.

Ainda nessa acepção, acreditamos que a AST, por seu caráter de "ponte" entre a crítica das forças produtivas na sociedade capitalista e a possibilidade de desconstrução e construção da tecnologia num sentido desejado, é um estribo que os movimentos sociais poderão utilizar para "pressionar" a comunidade científica e o governo a conformar uma nova agenda de Política Científica e Tecnológica.

\section{Referências}

BIJKER, W. Of Bicycles, Bakelites, and Bulbs. Toward a Theory of Sociotechnical Change. Massachusetts: MIT Press, 1995.

DAGNINO, Renato. Em direção a uma estratégia para a redução da pobreza: a Economia Solidária e a Adequação Sócio-técnica In: OR GANIZAÇÃO DOS ESTADOS IBERO-AMERICANOS PARA A EDUCAÇÃO, A CIÊNCIA E A CULTURA, Sala de Lectura CTS+I de la OEI, 2002. Disponível em: $<$ http://www.campus-oei.org/salactsi/index.html $>$.

DAGNINO, Renato; BRANDÃO, Flavio; NOVAES, Henrique. Sobre o marco analítico-conceitual da Tecnologia Social. In: DE PAULO, Antonio... et al.(Eds.). Tecnologia Social, uma estratégia para o desenvolvimento. [s.1.]: Fundação Banco do Brasil, 2004. p. 15-64.

FARIA, M. S. de. Autogestão, Cooperativa, Economia Solidária: avatares do trabalho e do capital. 2005. Tese (Doutorado em Sociologia Política). Florianópolis, UFSC, Sociologia Política, 2005. 
FEENBERG, A. Transforming technology. Oxford: University Press, 2002. FIORI, J. O poder global e a nova geopolítica das nações. São Paulo: Boitempo, 2007.

KATZ, J.; CIBOTTI, R. Marco de referencia para un programa de investigación en ciencia y tecnología en América Latina. Buenos Aires: Cepal, 1976.

MARSHALL, T. Cidadania, classe social e status. Rio de Janeiro: Labor, 1967.

NOGUEIRA, M. O pensamento político e a redemocratização do Brasil. Lua Nova. Revista de Cultura e Política, v.5, n.71, p. 197-227, 2007.

NÚÑEZ, J. La ciencia y la tecnología como procesos sociales. Lo que la educación científica no debería olvidar.2000. Disponível em:<www. campus-oei.org/salactsi/nunez00.htm>; <http://www.oei.es/revistactsi/ numero7/articulo02.htm>

O’DONNELL, G. Anotações para uma teoria do Estado. Revista de Cultura e Política, n.4, 1981.

OSZLAK, O. Estado e Sociedade: Novas Regras do Jogo? [México: Fondo de Cultura Econômica, 1994]. 